\title{
Influence of tungsten substitution and oxygen deficiency on the thermoelectric properties of $\mathrm{CaMnO}_{3-\delta}$
}

\author{
Philipp Thiel, ${ }^{1}$ James Eilertsen, ${ }^{1}$ Sascha Populoh, ${ }^{1, a)}$ Gesine Saucke, ${ }^{1}$ Max Döbeli, ${ }^{2}$ \\ Andrey Shkabko, ${ }^{1}$ Leyre Sagarna, ${ }^{1}$ Lassi Karvonen, ${ }^{1}$ and Anke Weidenkaff ${ }^{1,3}$ \\ ${ }^{1}$ Laboratory for Solid State Chemistry and Catalysis, Empa, Swiss Federal Laboratories for Materials Science \\ and Technology, Überlandstrasse 129, CH-8600 Dübendorf, Switzerland \\ ${ }^{2}$ Ion Beam Physics, Schafmattstrasse 20, ETH Hönggerberg, Swiss Federal Institute of Technology, \\ CH-8093 Zürich, Switzerland \\ ${ }^{3}$ Materials Chemistry, Institute for Materials Science, University of Stuttgart, Heisenbergstr. 3 , \\ DE-70569 Stuttgart, Germany
}

(Received 30 October 2013; accepted 9 December 2013; published online 27 December 2013)

\begin{abstract}
Polycrystalline tungsten-substituted $\mathrm{CaMn}_{1-x} \mathrm{~W}_{x} \mathrm{O}_{3-\delta}(0.00 \leq x \leq 0.05)$ powders were synthesized from a polymeric precursor, pressed and sintered to high density. The impact of tungsten substitution on the crystal structure, thermal stability, phase transition, electronic and thermal transport properties is assessed. Tungsten acts as an electron donator and strongly affects high-temperature oxygen stoichiometry. Oxygen vacancies form in the high figure-of-merit (ZT)-region starting from about $T=1000 \mathrm{~K}$ and dominate the carrier concentration and electronic transport far more than the tungsten substitution. The analysis of the transport properties yields that in the investigated regime the band filling is sufficiently high to overcome barriers of polaron transport. Therefore, the Cutler-Mott approach describes the electrical transport more accurately than the Mott approach for small polaron transport. The lattice thermal conductivity near room temperature is strongly suppressed with increasing tungsten concentration due to mass-difference impurity scattering. A ZT of 0.25 was found for $x=0.04$ at $1225 \mathrm{~K}$. (C) 2013 AIP Publishing LLC. [http://dx.doi.org/10.1063/1.4854475]
\end{abstract}

\section{INTRODUCTION}

Thermoelectric materials are a promising solution to the global demand for electricity. Modules constructed from thermoelectrics can generate emission-free energy when subjected to a thermal gradient provided by, e.g., solar or geothermal heat. They are robust, with no actuating components, and scalable from micro- to kilowatts. Therefore, they can also be employed to increase the conversion efficiency of heat-generating processes (e.g., heat engines) by exploiting waste heat. ${ }^{1}$

The conversion efficiency of thermoelectric materials depends on (1) the magnitude of the dimensionless figure-ofmerit, $Z T: Z T=S^{2} \sigma T / \kappa$ where $S$ is the Seebeck coefficient, $\sigma$ the electrical conductivity, $T$ the absolute temperature, and $\kappa$ the thermal conductivity; and (2) the Carnot efficiency, which increases with increasing temperature gradients. ${ }^{2}$ Thermoelectric materials that can withstand high-temperature applications (i.e., $T>1000 \mathrm{~K}$ ) are particularly suited for waste-heat and solar-energy harvesting. ${ }^{3,4}$ The maximum operating temperatures for standard thermoelectric materials, e.g., bismuth telluride $\left(T_{\operatorname{Max}}=550 \mathrm{~K}\right){ }^{5}$ half-Heusler compounds $\left(T_{\text {Max }}=850 \mathrm{~K}\right),{ }^{6,7}$ and skutterudites $\left(T_{\text {Max }}<673 \mathrm{~K}\right),{ }^{8,9}$ are moderately low. Moreover, these materials deteriorate in oxidizing atmospheres. Silicon germanium is stable until temperatures over $1300 \mathrm{~K}$, but oxidizes at elevated temperatures when operated in air, and is far too expensive to be used in large-scale

\footnotetext{
a) Author to whom correspondence should be addressed. Electronic mail: sascha.populoh@empa.ch
}

applications. ${ }^{10}$ Consequently, research focused on the discovery of high-efficiency and high-temperature stable materials is imperative for the development of viable thermoelectric modules for high-temperature applications. Perovskite-type calcium manganates $\left(\mathrm{CaMnO}_{3-\delta}\right)$ are stable in air at temperatures exceeding $1200 \mathrm{~K} .{ }^{11,12}$ They are synthesized from inexpensive and non-toxic materials, and exhibit relatively high $Z T$ 's, in excess of 0.15 at $1000 \mathrm{~K},{ }^{12,13}$ when appropriately substituted. Such materials are applicable as n-type thermoelectrics in all-oxide thermoelectric converters. ${ }^{14}$ Power-densities of up to $240 \mathrm{~mW} / \mathrm{cm}^{2}$ are reached with converters operated in air.

The Seebeck coefficient $(S)$ of pristine $\mathrm{CaMnO}_{3-\delta}$ is appropriately high $(-450 \mu \mathrm{V} / \mathrm{K})$, but the electrical conductivity is too low $(\rho(T)>0.1 \Omega \mathrm{cm}$; for room temperature $(\mathrm{RT})<T<800 \mathrm{~K}$ ) for thermoelectric applications. The magnitude of the Seebeck coefficient and the electrical conductivity depend inversely to each other from the charge carrier concentration, a compromise in substituent concentrations is essential for maximizing the power factor $\left(S^{2} \sigma\right)$. The power factor has been enhanced by A-site substitution with strontium, rhenium, or lanthanides, ${ }^{15-19}$ and B-site substitution with transition metals such as tantalum, molybdenum, niobium or ruthenium. ${ }^{13,20-23}$ Aliovalent B-site substitutions of no more than a few percent are particularly promising. For example $\mathrm{CaMn}_{0.98} \mathrm{Nb}_{0.02} \mathrm{O}_{3-\delta}$ exhibits a high Seebeck coefficient and electrical conductivity at elevated temperatures, and due to a concomitant reduction of the thermal conductivity, a maximum $Z T$ of 0.3 at $1070 \mathrm{~K}$ is attained. ${ }^{13}$

In addition to aliovalent substitution, research focused on the calcium manganates has revealed a strong correlation 
between electronic transport and variations in oxygen stoichiometry, particularly at elevated temperatures. For example, changes in oxygen content, observed in the calcium manganates, generate additional charge carriers that vary both Seebeck coefficient and electrical conductivity. ${ }^{24-28}$ The effect of oxygen deficiencies on the transport properties of un-substituted $\mathrm{CaMnO}_{3}$ has been studied by Goldyreva et al. ${ }^{24,25,29}$ Their studies demonstrated that increased oxygen deficiency, induced by a measurement atmosphere with reduced oxygen partial pressure, lowers the absolute value of the Seebeck coefficient and increases the electrical conductivity. This reduction does not immediately initiate a change of crystal structure, as the orthorhombic lattice can be preserved under moderate oxygen loss. ${ }^{30,31}$ Upon further reduction and thermal lattice expansion, a destabilization of the orthorhombic crystal occurs, ${ }^{24}$ resulting in a cubic phase at about $1200 \mathrm{~K}$. This crystal structure with higher symmetry is significantly more conductive due to a linear arrangement of $\mathrm{Mn}-\mathrm{O}-\mathrm{Mn}$ bonds. A decrease in Seebeck coefficient is observed, which lowers the power factor significantly. ${ }^{28}$ Both processes-the continuous loss of oxygen and the orthorhombic to cubic phase-transition-are entirely reversible in air. Therefore, $\mathrm{CaMnO}_{3-\delta}$-based materials with appropriate substitution may be employed for fluctuating-, high-temperature applications.

The influence of B-site tungsten substitution on magnetic, structural, and thermoelectric properties, from $15 \mathrm{~K}$ to room temperature, was investigated previously. ${ }^{32,33}$ It was shown that tungsten can substitute manganese in the $\mathrm{CaMnO}_{3-\delta}$ crystal lattice up to a solubility limit of $20 \%$. Up to $7 \%$ substitution level the Pnma space group of the pristine $\mathrm{CaMnO}_{3-\delta}$ is preserved. Alfaruq et al. demonstrated a significant enhancement of the high-temperature thermoelectric properties of $\mathrm{CaMnO}_{3}$ due to tungsten substitution. ${ }^{34}$ Tungsten is an ideal candidate for B-site substitution as it adds two additional negative charge carriers to the $\mathrm{Mn}^{4+}$ sublattice ${ }^{33}$ and is also more than three times heavier than manganese. Consequently, lattice thermal conductivity can be suppressed significantly by mass-difference impurity scattering. ${ }^{35}$ Moreover, tungsten (in addition to calcium and manganese) is nontoxic, abundant, and relatively inexpensive. This study investigates the combined effect of both the tungsten substitution on the B-site up to $5 \%$ and the concomitant reduction in oxygen content on the structural, chemical, and thermoelectric properties of $\mathrm{CaMnO}_{3}$. Tungsten-substituted $\mathrm{CaMn}_{1-x} \mathrm{~W}_{x} \mathrm{O}_{3-\delta} ; x \leq 0.05$ was synthesized via the citrate process, a modified Pechini method using citric acid as the chelating agent. ${ }^{36} \mathrm{~A} \mathrm{~W}$-peroxo complex was used in the precursor solution because it combusts without residual solid byproducts. This is beneficial compared to precursor solution prepared from transition metal chlorides, where metal chlorides might remain as byproducts.

\section{EXPERIMENTAL}

Polycrystalline perovskite-type calcium manganates with B-site tungsten substitution $\left(\mathrm{CaMn}_{1-x} \mathrm{~W}_{x} \mathrm{O}_{3-\delta} ; 0.00 \leq x \leq 0.05\right)$ were reproducibly synthesized by a soft chemistry (SC) method. ${ }^{13,37}$ For the synthesis of $0.1 \mathrm{~mol} \mathrm{CaMn}_{1-x} \mathrm{~W}_{x} \mathrm{O}_{3-\delta}$; $0.00 \leq x \leq 0.05 \quad 1$ equivalent (eq.) of $\mathrm{Ca}\left(\mathrm{NO}_{3}\right)_{2} \cdot 4 \mathrm{H}_{2} \mathrm{O}$
(Merck, analytical grade), $(1-x)$ eq. $\mathrm{Mn}\left(\mathrm{NO}_{3}\right)_{2} \cdot 4 \mathrm{H}_{2} \mathrm{O}$ (Merck, analytical grade) and 4 eq. of citric acid (Sigma Aldrich, 99\%) were dissolved in $250 \mathrm{ml}$ ultrapure water $(\sigma=18.2 \mu \mathrm{S})$. Elemental tungsten was oxidized in hydrogen peroxide to a peroxo-complex. ${ }^{38}$ Therefore $x$ eq. tungsten powder (Merck, fine powder $99+\%$ ) is added to 33\% hydrogen peroxide in aqueous solution (VWR, synthesis grade; $3 \mathrm{ml}$ per $100 \mathrm{mg} \mathrm{W}$ ) and stirred at $T=348 \mathrm{~K}$ for $4 \mathrm{~h}$. The tungsten solution was added to the solution of the nitrates. The combined solutions are refluxed for $4 \mathrm{~h}$ for complete polymerization, transferred into a crystallization dish, and then dried at $373 \mathrm{~K}$ for $12 \mathrm{~h}$ in a drying oven. The obtained xerogel was pre-decomposed by heating it at a rate of $20 \mathrm{~K} / \mathrm{h}$ to $553 \mathrm{~K}$ and holding it for $4 \mathrm{~h}$. The product was crushed, loaded into alumina crucibles, heated to $1373 \mathrm{~K}$ at a rate of $300 \mathrm{~K} / \mathrm{h}$, and calcined for $8 \mathrm{~h}$. The obtained polycrystalline powder was pressed in a circular steel die $(\varnothing=13 \mathrm{~mm})$ with $35 \mathrm{MPa}$ of uniaxial pressure, then transferred to a hydrostatic press, and pressed with $200 \mathrm{MPa}$ of isostatic pressure. The resultant green-bodies were sintered at $1523 \mathrm{~K}$. They were heated at a rate of $20 \mathrm{~K} / \mathrm{min}$ to the sintering temperature, the temperature was held for $5 \mathrm{~h}$, and then reduced to $1373 \mathrm{~K}$ at a rate of $5 \mathrm{~K} / \mathrm{min}$. Finally, the samples were cooled slowly $(0.3 \mathrm{~K} / \mathrm{min})$ through the phase-transition temperature to avoid thermal strains. Pellets with densities of more than $92 \%$ the theoretical density were obtained. Densities were determined by the Archimedes method. The results were checked by the determination of geometry and weight, accordingly the error is estimated to be $2 \%$.

Powder X-ray diffraction (XRD) data of all samples were collected using a PANanalytical X'Pert PRO system equipped with an $\mathrm{X}^{\prime}$ Celerator linear detector operating in Bragg-Brentano geometry $(\theta / 2 \theta)$ and a Johansson monochromator $\left(\mathrm{Cu}-\mathrm{K}_{\alpha 1}\right.$ radiation, $\left.1.5406 \AA\right)$. The samples were ground, mixed with silicon powder (AlfaAesar, crystalline, 99.999\%) as an internal standard, and loaded onto near-zero background silicon-wafer sample holders. The diffraction patterns were recorded between $10^{\circ}$ and $130^{\circ}(2 \theta)$ with an angular step interval of $0.0042^{\circ}$. Peak-profiles (position and shape) were determined by using the LeBail technique ${ }^{39}$ as implemented in the Fullprof program. ${ }^{40}$

X-ray photoemission spectroscopy (XPS) measurements were performed using a PHI Quantum 2000 spectrometer with monochromatic $\mathrm{Al} \mathrm{K}_{\alpha} \mathrm{X}$-rays $(1486.6 \mathrm{eV})$ and a hemispherical capacitor electron-energy analyzer equipped with a channel plate and a position-sensitive detector. Further details on experiment, quantitative analysis and expected precision are given elsewhere. ${ }^{41}$ The tungsten concentration is normalized to the total content of calcium, manganese, and tungsten. Furthermore, the samples were characterized by Rutherford backscattering spectrometry (RBS). ${ }^{42}$ Measurements were performed using a $2 \mathrm{MeV} 4 \mathrm{He}$ beam and a silicon PIN diode detector under $168^{\circ}$. The collected RBS data were simulated using the RUMP software. ${ }^{43}$

The morphology of the sintered samples was analyzed with scanning electron microscopy (SEM; Hitachi S4800 and XL30 ESEM (FEI)) with a secondary electron detector. 
The heat capacities $\left(C_{p}\right)$ and the phase-transition temperatures were determined using differential scanning calorimetry (DSC) using a Netzsch DSC 404C Pegasus. The imprecision of $C_{p}$ is $2.5 \%$ according to the manufacturer. The phase-transition temperatures were determined from the onset temperature of the signal peak upon heating at a rate of $20 \mathrm{~K} / \mathrm{min}$. From the imprecision of the temperature control and statistical considerations, the total error is around $\pm 4 \mathrm{~K}$.

The thermoelectric properties were measured from $323 \mathrm{~K}$ to $1273 \mathrm{~K}$ in air. Samples for thermoelectric property measurements were taken on the same sintered body. Resistivity $(\rho)$ and Seebeck coefficient $(S)$ measurements were carried out using an Ozawa Science RZ200li on bar shaped samples cut from the as-sintered pellets following the diffusivity measurements. The imprecision in $\mathrm{S}$ and $\rho$ is assumed to be $5 \%{ }^{44}$

The total thermal conductivity $(\kappa)$ was calculated from the thermal diffusivity $\alpha$, the heat capacity at constant pressure $C_{p}$ measured via DSC and the density d, applying the following relation: $\kappa=\alpha \cdot C_{p} \cdot d$. The thermal diffusivity was determined using a Netzsch LFA 457 laser flash apparatus. The detailed experimental procedures for the measurements of $\alpha$ and $C_{p}$ are described elsewhere. ${ }^{13}$ The combined error in $\kappa$ estimated with $10 \%{ }^{44}$

The oxygen contents of the $\mathrm{CaMn}_{1-x} \mathrm{~W}_{x} \mathrm{O}_{3-\delta}$ samples were determined by thermo-gravimetric analysis (TGA) using a Netzsch STA 409 CD thermobalance. Powder samples of $100 \mathrm{mg}$ were heated from $313 \mathrm{~K}$ up to $1473 \mathrm{~K}$ at a rate of $7.5 \mathrm{~K} / \mathrm{min}(155 \mathrm{~min}$ of total measurement time) under a reducing atmosphere $\left(5 \mathrm{vol} . \% \mathrm{H}_{2} / \mathrm{He}\right)$. The end-point of the reduction process was recognized from a constant high-temperature weight platform. The oxygen content $(3-\delta)$ was calculated using the observed relative weight loss. In this procedure, the correct $\delta$ value is searched through adjusting the theoretical relative weight difference between the total molar masses of the solid (s) sample material and the solid residual mixturebased on the equation below- to equal with the observed experimental relative weight loss:

$$
\begin{aligned}
& \mathrm{CaMn}_{1-x} W_{x} \mathrm{O}_{3-\delta}(s)+(1-2 x-\delta) \mathrm{H}_{2}(g) \stackrel{1473 \mathrm{~K}}{\longrightarrow} \mathrm{CaO}(s) \\
& \quad+(1-x) \mathrm{MnO}(s)+x \mathrm{WO}_{3}(s) \\
& \quad+(1-2 x-\delta) \mathrm{H}_{2} \mathrm{O}(g) .
\end{aligned}
$$

The proposed oxide mixture/solid solution was verified from the residual powders using XRD. In the case of the minute amounts of $\mathrm{W}$, the final hexavalent oxidation state was confirmed using XPS. Additionally, thermo-stability experiments were performed using TGA in synthetic air $(20.5 \%$ $\mathrm{O}_{2} / 79.5 \% \mathrm{~N}_{2}$ ), with further experimental details described elsewhere. ${ }^{28,45}$

\section{RESULTS AND DISCUSSIONS}

Phase-purity of the un-substituted and tungstensubstituted samples was verified by powder X-ray diffraction. All reflections, aside from those associated with the silicon internal standard, were assigned to an orthorhombictype crystal structure (Pnma space group). The orthorhombic $\mathrm{CaMnO}_{3-\delta}$ lattice expands with increasing tungsten substitution (Table I). All lattice parameters (a, b, and c) expand linearly, consistent with Vegard's law (Figure 1). ${ }^{46}$ The expansion is consistent with the unit cell increase reported in a niobium-substituted $\mathrm{CaMnO}_{3 \pm \delta}$ series. ${ }^{13}$ A systematic increase in non-uniform crystallite strain of $350 \%$ is observed and coincides with the increasing tungsten content (from $x=0.00$ to $x=0.05$ ). This strain is typical of partially substituted crystal structures, and can be interpreted as an increased distribution of lattice parameters due to the slight inhomogeneity in tungsten concentration throughout the crystallites. ${ }^{47-49}$

XPS measurements show a systematic increase of W $4 f$ intensity with tungsten content $x$ (Figure 2). The observed tungsten content $x_{o b s}$ is similar to the nominal tungsten content $x_{\text {nom }}$ differing less than $0.005 \mathrm{~mol}$ from $x_{\text {nom }}$. (Table II). The binding energy difference $\Delta \mathrm{BE}\left(\mathrm{W} 4 f_{7 / 2}-\mathrm{O} 2 p\right)=36.2 \mathrm{eV}-530.0 \mathrm{eV}$ $=493.8 \mathrm{eV}$ which normally indicates the interatomic distance between $\mathrm{W}$ and $\mathrm{O}$ corresponds to $\mathrm{W}^{6+}$ ions as it is found in the $\mathrm{W}^{6+} \mathrm{O}^{2-}{ }_{3}$ compound. ${ }^{50} \mathrm{~W}^{6+}$ is also the most likely oxidation state derived from the expected ionic radii $r$ for a substituent of $\left[\mathrm{Mn}^{4+}\right]$ ions (for coordination number 6: $r\left(\mathrm{Mn}^{4+}\right)=0.53 \AA$ $\left.<r\left(\mathrm{~W}^{6+}\right)=0.60 \AA<r\left(\mathrm{~W}^{5+}\right)=0.62 \AA<r\left(\mathrm{~W}^{4+}\right)=0.66 \AA\right) .{ }^{51}$ Furthermore, the elemental tungsten and manganese contents were confirmed with RBS (Table II). Both methods show good agreement in the tungsten content. For all samples, a slight tendency $(<3 \%)$ to B-site cationic deficiency is observed $\left(\left[\mathrm{Mn}^{\mathrm{x}+}\right]+\left[\mathrm{W}^{6+}\right]<\left[\mathrm{Ca}^{2+}\right]\right)$. This observation could be due to slight divinations in water content of hydrates used as starting materials.

The SEM image (Figure 3) shows the morphology of a sintered pellet representative for all the substitution levels and illustrates the low porosity of the samples (Table I). The shape of the individual particles is not present in the image.

\begin{tabular}{|c|c|c|c|c|c|c|c|c|}
\hline \multirow[b]{2}{*}{ Nominal W content [n/B-site] } & \multicolumn{3}{|c|}{ Lattice parameter } & \multirow[b]{2}{*}{$\chi^{2}$} & \multirow[b]{2}{*}{ Strain } & \multirow[b]{2}{*}{ Cell volume $\left(\AA^{3}\right)$} & \multirow[b]{2}{*}{ Theoretical density $\left(\mathrm{g} / \mathrm{cm}^{3}\right)$} & \multirow[b]{2}{*}{ Density $\left(\mathrm{g} / \mathrm{cm}^{3}\right)$} \\
\hline & $\mathrm{a}(\AA)$ & $\mathrm{b}(\AA)$ & $c(\AA)$ & & & & & \\
\hline 0.00 & 5.2782 & 7.4529 & 5.2695 & 1.67 & 6.72 & 207.29 & 4.583 & $4.22 \pm 0.08(92 \%)$ \\
\hline 0.01 & 5.2815 & 7.4570 & 5.2758 & 1.90 & 8.71 & 207.78 & 4.613 & $4.27 \pm 0.09(93 \%)$ \\
\hline 0.03 & 5.2887 & 7.4717 & 5.2907 & 1.87 & 13.56 & 209.07 & 4.667 & $4.39 \pm 0.09(94 \%)$ \\
\hline 0.04 & 5.2939 & 7.4755 & 5.2917 & 1.59 & 18.05 & 209.41 & 4.700 & $4.42 \pm 0.09(94 \%)$ \\
\hline 0.05 & 5.2959 & 7.4825 & 5.2964 & 1.84 & 23.88 & 209.88 & 4.730 & $4.44 \pm 0.09(94 \%)$ \\
\hline
\end{tabular}

TABLE I. Structural parameters after LeBail fitting and observed densities of the series $\mathrm{CaMn}_{1-x} \mathrm{~W}_{x} \mathrm{O}_{3-\delta}(0.00 \leq x \leq 0.05)$. Relative densities are calculated according to theoretical density derived from the cell volume and the molecular formula. 


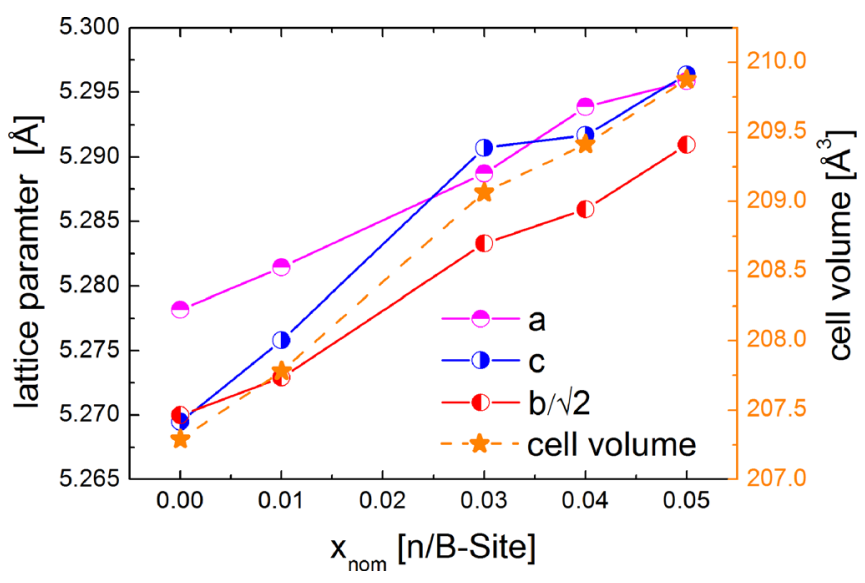

FIG. 1. Lattice parameters and cell volume of the $\mathrm{CaMn}_{1-x} \mathrm{~W}_{x} \mathrm{O}_{3-\delta}$ $(0.00 \leq x \leq 0.05)$ series plotted against the nominal W content $\left(x_{\text {nom }}\right)$.

Therefore assuming well sintered grains good electron- and phonon-transport can be expected. Results of oxygen deficiency derived from the TGA experiments are shown in Table II. The oxygen deficiency of pristine $\mathrm{CaMnO}_{3-\delta}$ ( $\delta=0.021)$ is the highest in the series. However, the tungsten substituted samples exhibit only little deviation from the ideal stoichiometry at room temperature $(\delta \approx 0)$, since $\mathrm{W}^{6+}$ has a higher ionic charge and its bonding to oxygen is stronger than that of $\mathrm{Mn}^{4+}$, likely constraining oxygen loss. The oxygen content is a dynamic feature depending on the ambient temperature and the oxygen partial pressure, which is indicated by weight changes during the TG measurements (Figure 4(a)). The un-substituted and tungsten-substituted samples release and recover oxygen in an entirely reversible manner. The same behavior was observed in the $\mathrm{Nb}$-substituted $\mathrm{CaMn}_{1-x} \mathrm{Nb}_{x} \mathrm{O}_{3-\delta} \quad(x=0.02,0.05,0.08)$ described by Bocher et al. ${ }^{28,45}$ For instance, the oxygen content of $\mathrm{CaMn}_{1-x} \mathrm{~W}_{x} \mathrm{O}_{3-\delta} x=0.01$ is stable in synthetic air until $T_{\text {red }}=1000 \pm 15 \mathrm{~K}$; however, above this temperature the sample releases oxygen steadily as the temperature is increased. Upon cooling, the sample recovers from the

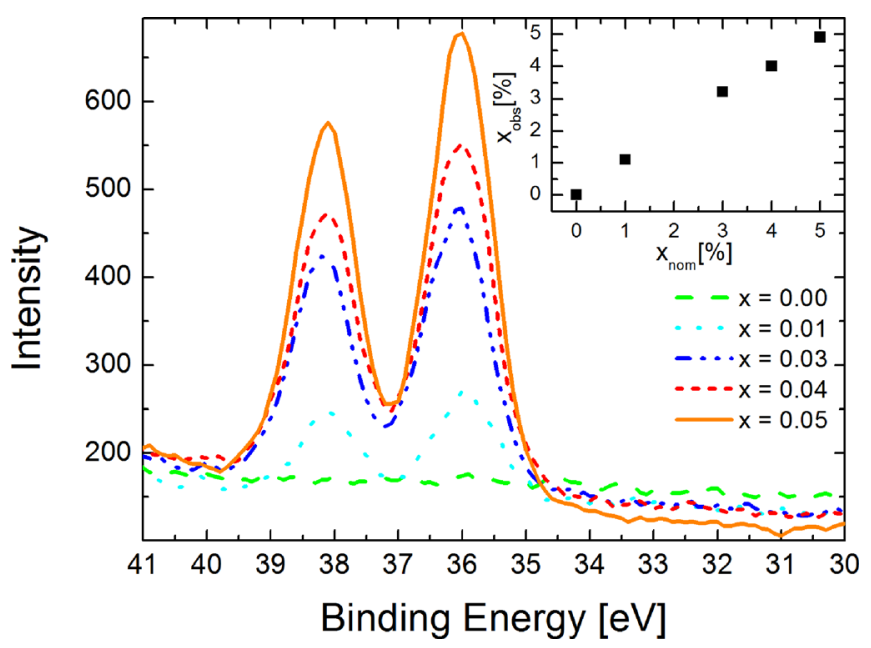

FIG. 2. X-ray photoemission spectrum of the $\mathrm{CaMn}_{1-x} \mathrm{~W}_{x} \mathrm{O}_{3-\delta}$ $(0.00 \leq x \leq 0.05)$ series. Shown are the $\mathrm{W} 4 f_{7 / 2}(\mathrm{BE}=36.0 \mathrm{eV})$ and $\mathrm{W} 4 f_{5 / 2}$ $(\mathrm{BE}=38.7 \mathrm{eV})$ intensities. The inset shows the dependence of observed $x_{\mathrm{obs}}$ from the nominal $x_{\text {nom }}$ tungsten content. oxygen loss completely (Figure 4(a)). The initiation temperature of oxygen loss increases with increasing level of tungsten substitution, reflecting the stronger binding effect of the $\mathrm{W}^{6+}$ towards $\mathrm{O}^{2-}$ as compared with $\mathrm{Mn}^{4+}$ (Figure 5). Dynamic oxygen loss was determined from powdered samples although the thermoelectric properties were measured on sintered samples. Since oxygen diffusion through the sintered material is expected to be slower compared to the powdered material, TG experiments were also performed on sintered material with the same heating program as the transport measurements to verify that the oxygen content reaches equilibrium at each measurement temperature. The behavior of the bar-shaped sintered $x=0.01 \mathrm{~W}$-substituted sample at reaching the plateau at $1205 \mathrm{~K}$ is shown (Figure $4(\mathrm{~b})$ ). No mass loss is observed by TGA after a dwell of 15 to $20 \mathrm{~min}$. Transport data are collected at a particular measurement temperature after a longer dwell determined by stability parameters. Consequently, the oxygen content can be assumed as stable at each measurement point during transport measurements.

Heat capacities of the orthorhombic and the cubic phases were determined by DSC measurements (Table II). A small decrease in the heat capacities is observed with increasing tungsten substitution as predicted by the Dulong-Petit law, although the decrease in is not significant due to the error, which has to be considered. For instance, the orthorhombic phase heat capacities (measured at $T=900 \mathrm{~K}$ ) are $C_{p}=822 \pm 21 \mathrm{~mJ} / \mathrm{gK}$ and $C_{p}=772 \pm 19 \mathrm{~mJ} / \mathrm{gK}$ for the unsubstituted $\mathrm{x}=0.00$ and $\mathrm{x}=0.05$ samples, respectively. The cubic phase heat capacity is considerably larger than the orthorhombic phase; it varies in the range of $C_{p}=1171 \pm 29 \mathrm{~mJ} / \mathrm{gK}$ and $C_{p}=1231 \pm 31 \mathrm{~mJ} / \mathrm{gK}$. In the DSC measurements, this phase-transition is indicated by a peak (Figure 9(b), inset). The phase-transition temperature (Table II) is, as well as the starting of the reversible reduction, dependent on the tungsten content. Pristine $\mathrm{CaMnO}_{3-\delta}$ has with $T=1171 \pm 4 \mathrm{~K}$ the lowest phase-transition temperature. The phase-transition temperatures are increased to $1243 \pm 4 \mathrm{~K}$ for $x=0.05$. The interconnection of reduction and phase-transition is also discussed by Leonidova et al. ${ }^{24}$ They report strong evidence that this high-temperature phase-transition is a consequence of the increased oxygen deficiency.

W substitution in $\mathrm{CaMn}_{1-x} \mathrm{~W}_{x} \mathrm{O}_{3-\delta}$ affects electric resistivity $\rho(T)$ significantly (Figure 6(a)). The un-substituted sample is insulating $\left((900 \pm 45) \times 10^{-3} \Omega \mathrm{cm}\right.$ at $\left.360 \mathrm{~K}\right)$ near RT with semiconducting temperature dependence $(\mathrm{d} \rho / \mathrm{d} T<0)$. The substituted samples are considerably more conductive $\left(<20 \times 10^{-3} \Omega \mathrm{cm}\right)$ near RT and metallic $(\mathrm{d} \rho / \mathrm{d} T>0)$ and there is a systematic decrease of $\rho(T)$ with $x$. The decrease is quite small for $0.03<x<0.05$ compositions indicating that a lower limit of $\rho$ is approached. For aliovalent A-site substituted $\mathrm{CaMnO}_{3-\delta}$, this lower limit has already been discussed. The lowest $\rho$ was found in pentavalent-substituted $\mathrm{CaMnO}_{3-\delta}$ with $10 \%-12 \%$ additional negative charge carriers. ${ }^{52}$ Consequently, the lowest $\rho$ for hexavalent W(VI)-substituted might be expected for $x=0.05-0.06$. Wang et al. proposed charge ordering effects to explain this saturation phenomenon. ${ }^{52}$ But alternatives to charge ordering, especially in manganates, have been 
TABLE II. Elemental composition, heat capacity, and phase-transition temperatures of the $\mathrm{CaMn}_{1-x} \mathrm{~W}_{x} \mathrm{O}_{3-\delta}(0.00 \leq x \leq 0.05)$ series.

\begin{tabular}{|c|c|c|c|c|c|c|c|}
\hline \multirow[b]{2}{*}{$\begin{array}{l}\text { Nominal W } \\
\text { content [n/B-site] }\end{array}$} & \multicolumn{4}{|c|}{ Composition } & \multicolumn{3}{|c|}{ Heat capacity $C_{p}$} \\
\hline & $\begin{array}{c}\text { W content by XPS } \\
\text { [n/B-Site }]\end{array}$ & $\begin{array}{l}\text { W content by } \\
\text { RBS [n/B-Site] }\end{array}$ & $\begin{array}{c}\text { Mn content by RBS } \\
\text { [n/B-Site }]\end{array}$ & $\begin{array}{l}\text { O deficiency } \\
\delta \text { by TG }\end{array}$ & $\begin{array}{l}\text { Phase-transition } \\
\text { temperature }(\mathrm{K})\end{array}$ & $\begin{array}{l}\text { Orthorhombic phase } \\
T=900 \mathrm{~K}(\mathrm{~mJ} / \mathrm{gK})\end{array}$ & $\begin{array}{c}\text { Cubic phase } \\
T=1350 \mathrm{~K}(\mathrm{~mJ} / \mathrm{gK})\end{array}$ \\
\hline 0.00 & 0.000 & 0.0012 & 0.98 & 0.021 & $1171 \pm 4$ & $822 \pm 21$ & $1414 \pm 35$ \\
\hline 0.01 & 0.011 & 0.0105 & 0.98 & 0.002 & $1190 \pm 4$ & $781 \pm 20$ & $1335 \pm 33$ \\
\hline 0.03 & 0.032 & 0.029 & 0.97 & 0.001 & $1231 \pm 4$ & $789 \pm 20$ & $1380 \pm 35$ \\
\hline 0.04 & 0.040 & 0.0415 & 0.94 & -0.001 & $1231 \pm 4$ & $752 \pm 19$ & $1271 \pm 32$ \\
\hline 0.05 & 0.049 & 0.05 & 0.95 & 0.001 & $1243 \pm 4$ & $772 \pm 19$ & $1372 \pm 34$ \\
\hline
\end{tabular}

proposed by many authors. ${ }^{53-55}$ An increase of negative charge-carrier concentration in manganates does not necessarily coincide with an increase of itinerant electrons. ${ }^{56} \mathrm{~A}$ higher population of Jahn-Teller active $\mathrm{Mn}^{3+} \mathrm{e}_{\mathrm{g}}$ orbitals cause localized states and therefore induce distortions in the conduction band and lower the electron mobility. Consequently, the increase of charge-carrier concentration in the $0.03<x<0.05$ compositions causes only a minor enhancement of electrical-conductivity. Similar considerations concerning the effect of Jahn-Teller distortions on the electrical conductivity have already been proposed by Miclau et al. ${ }^{33}$ These trends continue into the regime of oxygen loss where charge-carrier concentration increases due to the reduction of $\mathrm{Mn}^{4+}$ to $\mathrm{Mn}^{3+}$. The high-temperature electrical resistivity of lower or non-substituted samples is substantially more affected by the oxygen loss than the higher substituted samples. Despite substitution, the resistivity of pristine $\mathrm{CaMnO}_{3-\delta}\left((11.6 \pm 0.6) \times 10^{-3} \Omega \mathrm{cm}\right)$ is similar to that of the $x=0.01$ sample $\left((13.3 \pm 0.6) \times 10^{-3} \Omega \mathrm{cm}\right)$ at $1277 \mathrm{~K}$.

Electrical conductivity can be influenced strongly by bulk effects, such as grain morphology, and synthesis techniques. $^{57,58}$ The Seebeck coefficient $S(T)$, however, is not as susceptible to these effects and generally provides a more reliable indicator of conduction modes. Seebeck coefficient $S(T)$ data for the $\mathrm{CaMn}_{1-x} \mathrm{~W}_{x} \mathrm{O}_{3-\delta}(0.00 \leq x \leq 0.05)$ are shown in Figure 6(b). $S(T)$ values are in accordance with low-temperature data presented in literature. ${ }^{33}$ At room

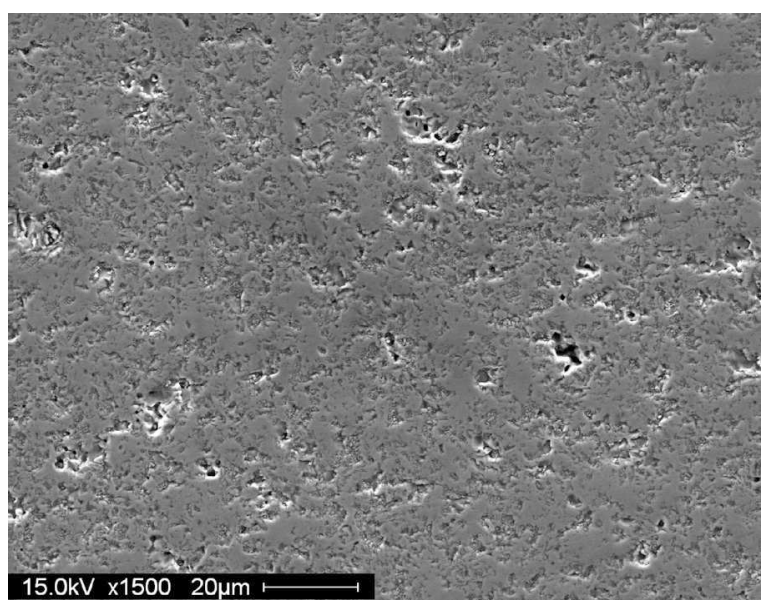

FIG. 3. Scanning electron microscopy image of a sintered $\mathrm{CaMn}_{1-\mathrm{x}} \mathrm{W}_{\mathrm{x}} \mathrm{O}_{3-\delta}$ $(\mathrm{x}=0.03)$ sample. The sample is representative for all substitution levels. temperature and above, pristine and $\mathrm{W}$-substituted $\mathrm{CaMnO}_{3-\delta}$ exhibit entirely different trends in $S(T)$. The Seebeck coefficient of pristine $\mathrm{CaMnO}_{3-\delta}$ is significantly higher in this regime $(S(T)<-400 \mu \mathrm{V} / \mathrm{K}$ for $R T<T>600 \mathrm{~K})$. Up to $900 \mathrm{~K}$ typical semiconducting behavior is observed: $|S(T)|$ decreases with increasing temperature. W-substituted $\mathrm{CaMnO}_{3-\delta}$ shows degenerate semiconductor behavior. $|S(T)|(\mathrm{RT}<T<1000 \mathrm{~K})$ of substituted $\mathrm{CaMnO}_{3-\delta}$ increases with temperature and decreases with $x_{\text {nom }}$. The oxygen-loss-induced increase of $\left[\mathrm{Mn}^{3+}\right]$ causes a drop in $|S|$ consistent with an increase in charge-carrier concentration; this can be understood as self-doping. The $S(T)$-curves converge in this regime providing further evidence that oxygen loss is a major source of negative charge carriers; the difference in Seebeck coefficients $\Delta S$ between samples is lowest at $T=1277 \mathrm{~K}(\Delta S=32 \mu \mathrm{V} / \mathrm{K})$.

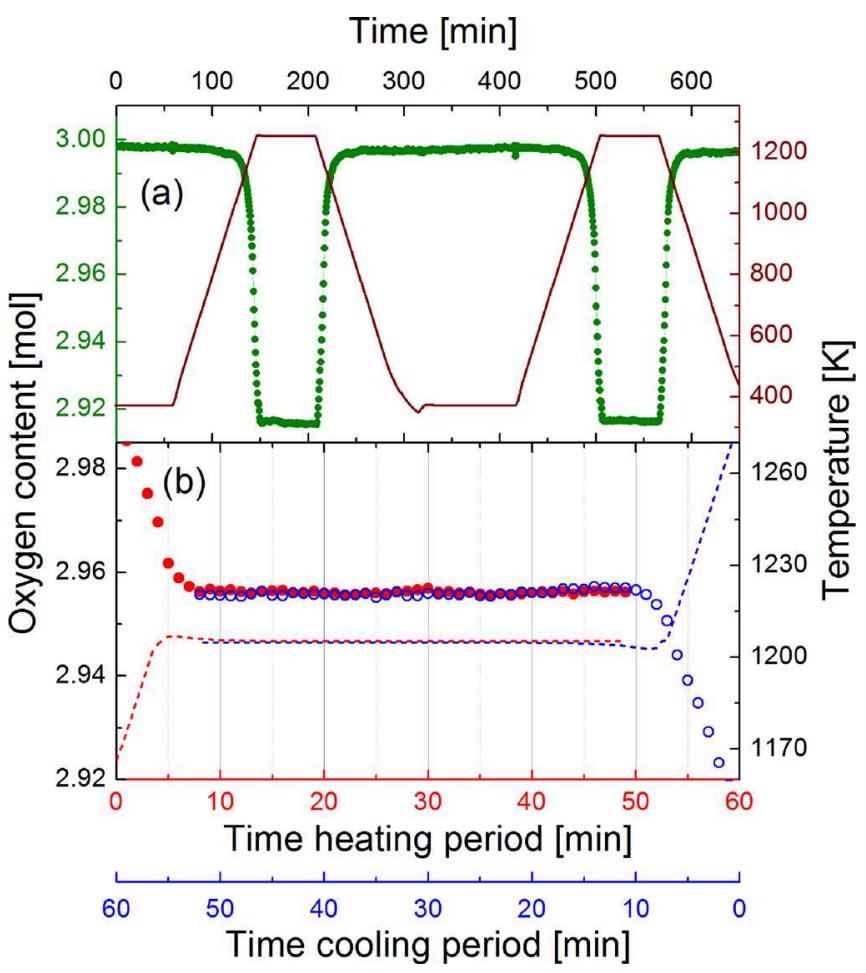

FIG. 4. Time dependent in situ thermo-gravimetric analyses of the oxygen loss and uptake of $\mathrm{CaMn}_{1-x} \mathrm{~W}_{x} \mathrm{O}_{3-\delta}(x=0.01)$ under heating and cooling cycles that simulate those used in transport measurements: (a) a powder sample and (b) a bar-shaped sample (as used for transport measurements). The figure depicts the plateau at $T=1205 \mathrm{~K}$ for both the heating and cooling cycles. 


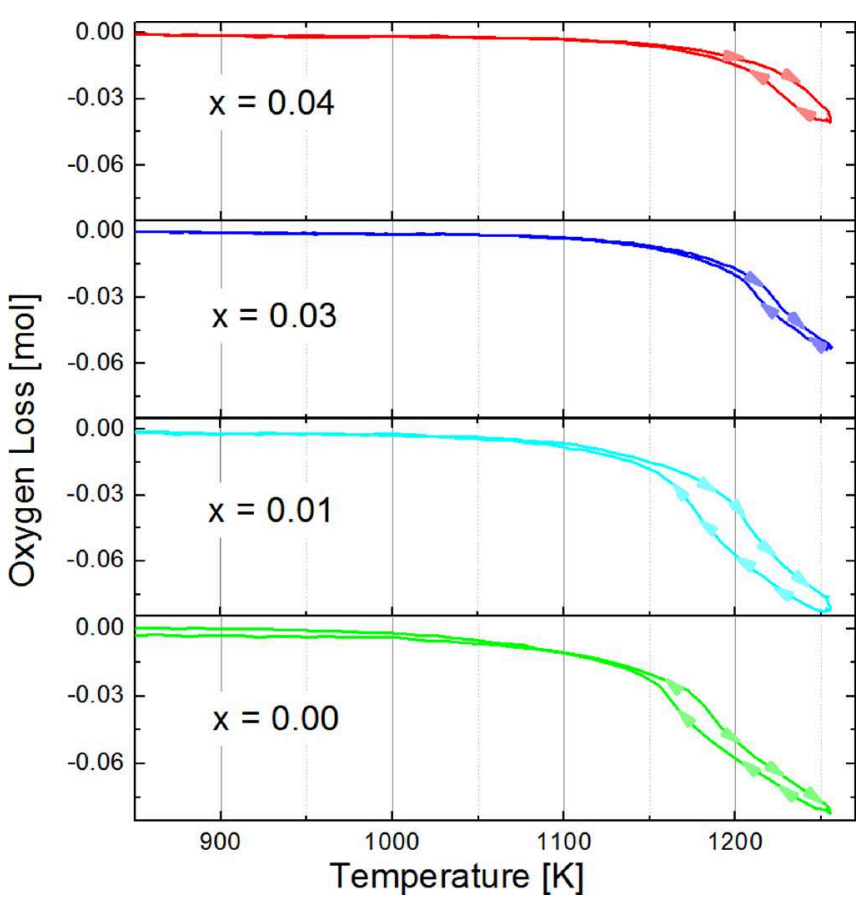

FIG. 5. Temperature dependent in situ thermo-gravimetric analyses of the oxygen loss and uptake of $\mathrm{CaMn}_{1-x} \mathrm{~W}_{x} \mathrm{O}_{3-\delta}(0.00 \leq \mathrm{x} \leq 0.04)$ on powder samples. Oxygen loss is delayed with increasing tungsten substitution.

Many studies claim that electron-doped $\mathrm{CaMnO}_{3-\delta}$ compounds are paramagnetic with polaron-like charge carriers. ${ }^{59-61}$ Therefore, Mott's adiabatic small-polaron conduction model can be used to quantify activation energy for conductivity and the Seebeck coefficient. The activation energy $\left(E_{a}\right)$ for electrical conductivity can be determined from the resistivity data according to the following formula (Figure 7(a), Table III): ${ }^{52,62,63}$

$$
\rho_{\text {Mott }}(T)=\rho_{0} T \exp \left(\frac{E_{a}}{k_{B} T}\right)
$$

(where $k_{b}$ is the Bolzmann constant, $e$ the elemental charge, $\rho_{O}$ is a constant factor, and $E_{a}$ is the activation energy of electrical conductivity). Moreover, Mott's adiabatic smallpolaron conduction model can also be used to quantify the activation energy from the Seebeck effect $\left(E_{s}\right)$

$$
S_{\text {Mott }}(T)=\frac{k_{B}}{e}\left(\frac{E_{S}}{k_{B} T}+\text { const. }\right)
$$

(where $E_{s}$ is the thermopower excitation energy). $E_{s}$ is fitted by plotting $\mathrm{S}$ against the reciprocal temperature $T^{-1}$ (Figure 7 (b), Table III); for all samples, $E_{s} \approx 25 \mathrm{meV}$. The value is similar to other reported A-site substitutions of $\mathrm{CaMnO}_{3-\delta} .{ }^{52}$

The high-temperature limit of the Seebeck coefficient $S_{T \rightarrow \infty, M o t t}(x)$ can be determined by extrapolating to the y-intercept $\left(T^{-1}=0\right)$ disregarding oxygen loss (Table III). Additionally, Heikes formula was used to determine the high-temperature limit of the Seebeck coefficient

$$
\lim _{T \rightarrow \infty} S_{\text {Heikes }}(y)= \pm \frac{k_{B}}{e} \ln g \frac{1-y}{y}
$$

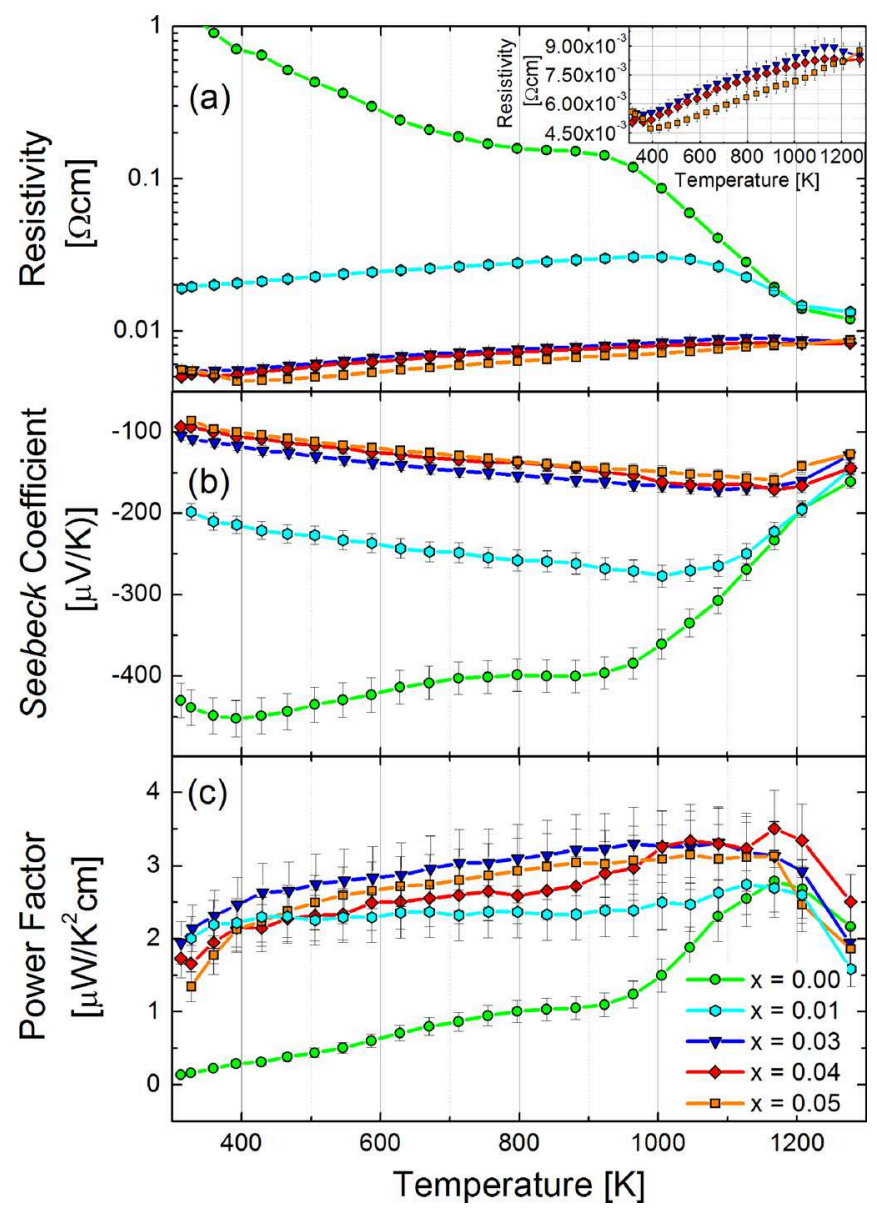

FIG. 6. Transport properties of the $\mathrm{CaMn}_{1-x} \mathrm{~W}_{x} \mathrm{O}_{3-\delta}(0.00 \leq x \leq 0.05)$ series as function of the temperature. (a) Logarithmic plot of the electrical resistivity. The inset shows a linear plot of the resistivity $(\rho)$ for $0.03 \leq x \leq 0.05$. (b) Seebeck coefficient (S): Absolute values decrease with substitution level. (c) Power factor $S^{2} \rho^{-1}$.

(where $g$ is a degeneracy factor taking variable spins of charge carriers into account, and y the charge carrier concentration). Considering a hopping conduction mode and the degeneracy of the electron spins in the $\mathrm{Mn}^{4+} / \mathrm{Mn}^{3+}$ system, $g=4 / 9$ in electron-doped $\mathrm{CaMnO}_{3}{ }^{64}$ the charge-carrier concentration is $y=N / N_{A} \approx\left[\mathrm{Mn}^{3+}\right]$, where $N / N_{A}$ is the number of charge carriers $N$ per available site $N_{A}$. For $y=2 \cdot x_{o b s}$ (assuming every substituted $\mathrm{W}^{6+}$ creates two $\mathrm{Mn}^{3+}$ ), the $S_{T=\infty, g, \text { Heikes }}\left(x_{o b s}\right)$ values are in good accordance with the extrapolated high-temperature Seebeck coefficients $S_{T=\infty, M o t t}(x)$ (Table III). Although Heikes formula is valid for the high-temperature limit, relative changes in the temperature dependent Seebeck coefficient can be discussed as functions of $\mathrm{W}$ concentration and oxygen loss as well. For all substituted samples, before reduction, the isothermal (RT $<T<T_{R e d}$ ) Seebeck coefficient $\left(S_{T}\left(x_{o b s}\right)\right)$ depends linearly on $\ln ((1-y) / y)$ with constants of proportionality $m=\mathrm{d} S / \mathrm{d}(\ln ((1-y) / y))$ between $-87.4 \mu \mathrm{V} / \mathrm{K}$ $<m<-80.0 \mu \mathrm{V} / \mathrm{K}$ (Figure 8(a)). Upon oxygen loss, a similar trend is found: $y$ depends on $x_{o b s}$ and the oxygen deficiency $\delta_{x}(T)$ which is a function of temperature, accordingly $y(T)=2 \cdot\left(x_{o b s}+\delta_{x}\right)$. The fitted constants of proportionality are $m=-84 \mu \mathrm{V} / \mathrm{K}$ and $m=-62 \mu \mathrm{V} / \mathrm{K}$ for pristine and $x_{\text {nom }}=0.01 \mathrm{CaMnO}_{3-\delta}$, respectively (Figure 8(b)). These 


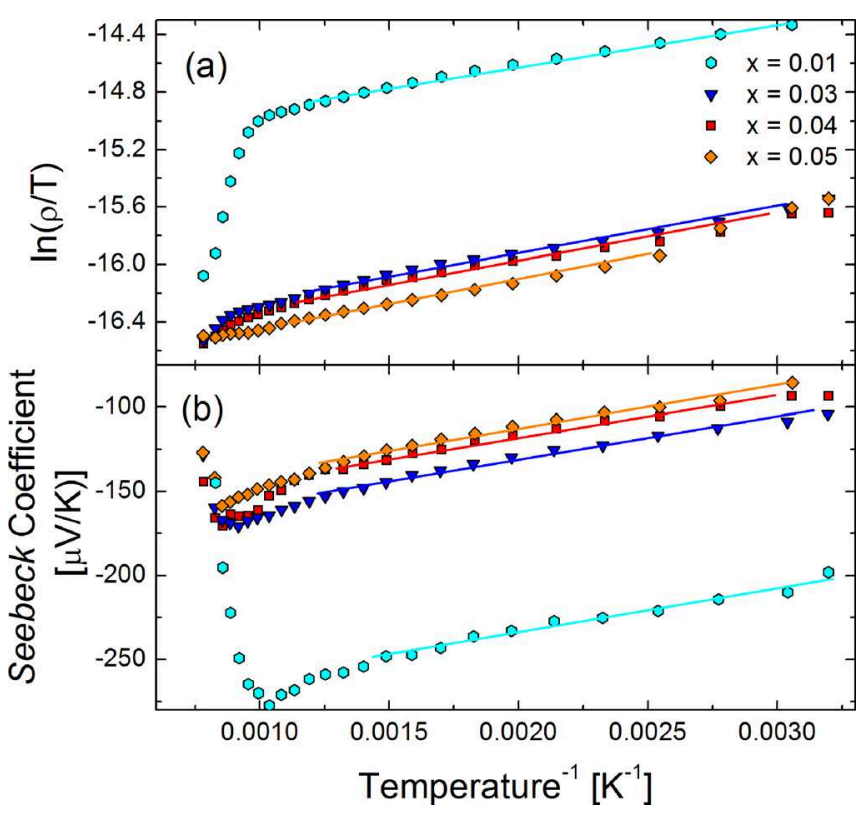

FIG. 7. Transport properties the $\mathrm{CaMn}_{1-x} \mathrm{~W}_{x} \mathrm{O}_{3-\delta}(0.00 \leq x \leq 0.05)$ series plotted against the reciprocal temperature $\left(T^{-1}\right)$ The graphs are evaluated in the static oxygen region below $T=800 \mathrm{~K}$, which corresponds to $T^{-1}=0.00125 \mathrm{~K}^{-1}$. (a) The action energy $\mathrm{E}_{\mathrm{a}}$ of the electrical conductivity is derived from the slope of the $\ln (\rho / T)$ plot. (b) The action energy $E_{s}$ of the Seebeck effect is equal to the slope of the Seebeck coefficient plot. Both energies are presented in Table III.

fitting parameters are close to $-k_{B} / e=-86 \mu \mathrm{V} / \mathrm{K}$, satisfying the constants of proportionality from the Heikes formula.

A comparison of excitation energies $\left(E_{a}\right.$ and $\left.E_{s}\right)$ can help to validate the nature of the conduction of electrons in thermoelectric materials. For A-site substituted calcium manganates, Wang et al. found that $E_{a}$ is significantly larger than $E_{s}$. The difference represents half of the polarontransport activation energy $1 / 2 W=E_{a}-E_{s} .{ }^{52}$ This result is characteristic of electron transport due to polarons. ${ }^{63}$ For the $\mathrm{B}$-site $\mathrm{W}$-substituted samples, $E_{a}$ is similar to $E_{s}$ for all samples (Table III). Although a $T^{-1}$ dependence is observed, a near-zero polaron-transport activation energy $W$ indicates that a thermally activated hopping mechanism is unlikely and band conduction mechanism can be assumed (cf. Refs. 62 and 63). This is explained by the formation of impurity bands due to substitution into the conductive network on the B-site. ${ }^{65}$ The energy level of maximum band filling at a certain doping and temperature can be denoted with $E_{f}(x, T)$ and the separation of the localized states of the electrons with $E_{C} . W \approx 0$ implies that $E_{f} \geq E_{C} \cdot{ }^{66}$ For this case Cutler and Mott proposed a metal-like description of the Seebeck coefficient, where $N(E)$ is the density of states and the parameter $\mu_{0}=e \lambda_{s}^{2} / \tau_{0} k T$ depending on the mean free path $\lambda_{s}{ }^{2}$ (Ref. 66)

$$
S(T)=-\pi^{2} \frac{k_{B}}{3 e}\left(k_{B} T \frac{\partial \ln \left(\mu_{0} N(E)\right)}{\partial E}-\frac{\partial W(E)}{\partial E}\right)_{E=E_{F}} .
$$

The fit parameter $\left(\delta \ln \left(\mu_{0} N(E)\right) / \delta E\right)^{-1}$ for the curve of the tungsten-substituted samples up to $1000 \mathrm{~K}$ is merely dependent from the dopant concentration with values between -0.26 and $-0.33 \mathrm{eV}$ (Table III). This behavior agrees with other studies on manganates. ${ }^{67,68}$ The derivative $\delta W(E) / \delta E$ decreases with increasing substitution level $x$ from -0.646 to -0.258 . The decline of $\delta W(E) / \delta E$ is in agreement with $W(E)$ reaching asymptotically 0 with increasing $x$ as discussed by Cutler and Mott.

Tungsten substitution causes a particularly strong increase in power factor $\left(S^{2} \sigma\right)$ from $\mathrm{RT}$ to $1000 \mathrm{~K}$. The highest power factor in this temperature range, observed in the $x=0.03$ sample, reached $3.3 \pm 0.5 \mu \mathrm{W} / \mathrm{K}^{2} \mathrm{~cm}$ at $965 \mathrm{~K}$ (Figure 7(c)). Higher substitution causes a decrease in $S^{2} \sigma$, because of the stronger decrease of the Seebeck coefficient. Above $1000 \mathrm{~K}$ the influence of the substitution on the power factor is much smaller. This observation underlines the strong influence of oxygen content on the transport properties of $\mathrm{CaMnO}_{3 \pm \delta}$.

The lattice thermal conductivity $\left(\kappa_{\text {lattice }}\right)$ is approximated from the total thermal conductivity $\left(\kappa_{\text {total }}\right)$ according to the relation: $\kappa_{\text {total }}=\kappa_{\text {lattice }}+\kappa_{e l} . \kappa_{e l}$ is the electrical thermal conductivity derived from the Wiedemann-Franz law, $\kappa_{e l}=L T / \rho$, where the Sommerfeld value of the Lorenz number is $L=2.45 \times 10^{-8} \mathrm{~W} \Omega \mathrm{K}^{-2}{ }^{69}$ This is used for both the, un-substituted and tungsten-substituted samples (Figures 9(a) and 9(b)). Substitution decreases the lattice thermal conductivity significantly (up to $45 \%$ ) at low temperatures due to mass-difference, point-defect scattering of phonons. At higher temperatures Umklapp scattering is dominant, diminishing the observable effect of the mass-difference impurity scattering. Consequently, the thermal conductivity of the tungsten-substituted samples approaches the one of the un-substituted samples. ${ }^{70}$ The observed trends of the lattice thermal conductivities are in line with the expectation from the substitution levels. The lattice thermal conductivity

TABLE III. Electronic transport properties of the $\mathrm{CaMn}_{1-x} \mathrm{~W}_{x} \mathrm{O}_{3-\delta}(0.00 \leq x \leq 0.05)$ series.

\begin{tabular}{|c|c|c|c|c|c|}
\hline Nominal W content [\%/B-site] & 0.00 & 0.01 & 0.03 & 0.04 & 0.05 \\
\hline$S_{T=360 \mathrm{~K}}(\mu \mathrm{V} / \mathrm{K})$ & $-448 \pm 22$ & $-210 \pm 11$ & $-113 \pm 6$ & $-99.4 \pm 5$ & $-96.2 \pm 5$ \\
\hline$S_{T=1086 \mathrm{~K}}(\mu \mathrm{V} / \mathrm{K})$ & $-307 \pm 15$ & $-277 \pm 14$ & $-171 \pm 9$ & $-165 \pm 8$ & $-153 \pm 8$ \\
\hline$\rho_{\mathrm{T}=360 \mathrm{~K}}\left(10^{-3} \Omega \mathrm{cm}\right)$ & $950 \pm 50$ & $20.0 \pm 1$ & $5.45 \pm 0.3$ & $5.06 \pm 0.3$ & $5.21 \pm 0.3$ \\
\hline$\rho_{\mathrm{T}=1086 \mathrm{~K}}\left(10^{-3} \Omega \mathrm{cm}\right)$ & $40.9 \pm 2$ & $26.6 \pm 2$ & $8.42 \pm 0.4$ & $7.99 \pm 0.4$ & $7.15 \pm 0.4$ \\
\hline$E_{s}(\mathrm{meV})$ & & 26.6 & 25.8 & 25.5 & 26.6 \\
\hline$E_{a}(\mathrm{meV})$ & & 25.4 & 28.3 & 26.0 & 26.9 \\
\hline$S_{T=\infty, M o t t} \cdot(\mu \mathrm{V} / \mathrm{K})$ & & -287 & -183 & -169 & -165 \\
\hline$S_{T=\infty, \text { Heikes } \mathrm{g}=4 / 9}(\mu \mathrm{V} / \mathrm{K})$ & & -282 & -186 & -166 & -143 \\
\hline$\left(\delta \ln \left(\mu_{0} \mathrm{~N}(\mathrm{E})\right) / \delta \mathrm{E}\right)^{-1}(\mathrm{eV})$ & & -0.260 & -0.311 & -0.331 & -0.313 \\
\hline$\delta \mathrm{W} / \delta \mathrm{E}$ & & -0.646 & -0.330 & -0.281 & -0.258 \\
\hline
\end{tabular}




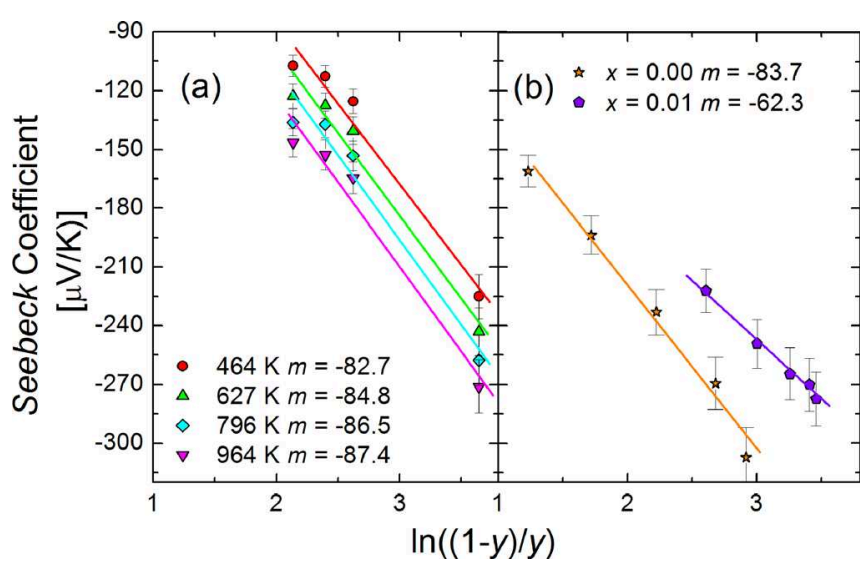

FIG. 8. Seebeck coefficient of the series $\mathrm{CaMn}_{1-x} \mathrm{~W}_{x} \mathrm{O}_{3-\delta}(0.00 \leq \mathrm{x} \leq 0.05)$ plotted against $\ln ((1-y) / y) .\left[\mathrm{Mn}^{3+}\right]\left(\mathrm{y} \approx\left[\mathrm{Mn}^{3+}\right]\right)$ is derived from $\mathrm{W}$ content and $\mathrm{O}$ deficiency. $m$ represents the slope $m=\mathrm{d} S / \mathrm{d}(\ln ((1-y) / y))$. (a) Constant temperature, stable oxygen content, variable $\mathrm{W}$ content. (b) High-temperature oxygen-deficient region. Constant $\mathrm{W}$ content, variable temperature, and oxygen deficiency.

increases considerably with the orthorhombic to cubic phase-transition due to the increased heat capacity and thermal diffusivity of the cubic phase.

The dimensionless figure-of-merit $(Z T)$ was calculated within the temperature range $375 \mathrm{~K}<T<1275 \mathrm{~K}$ (Figure 9(c)).

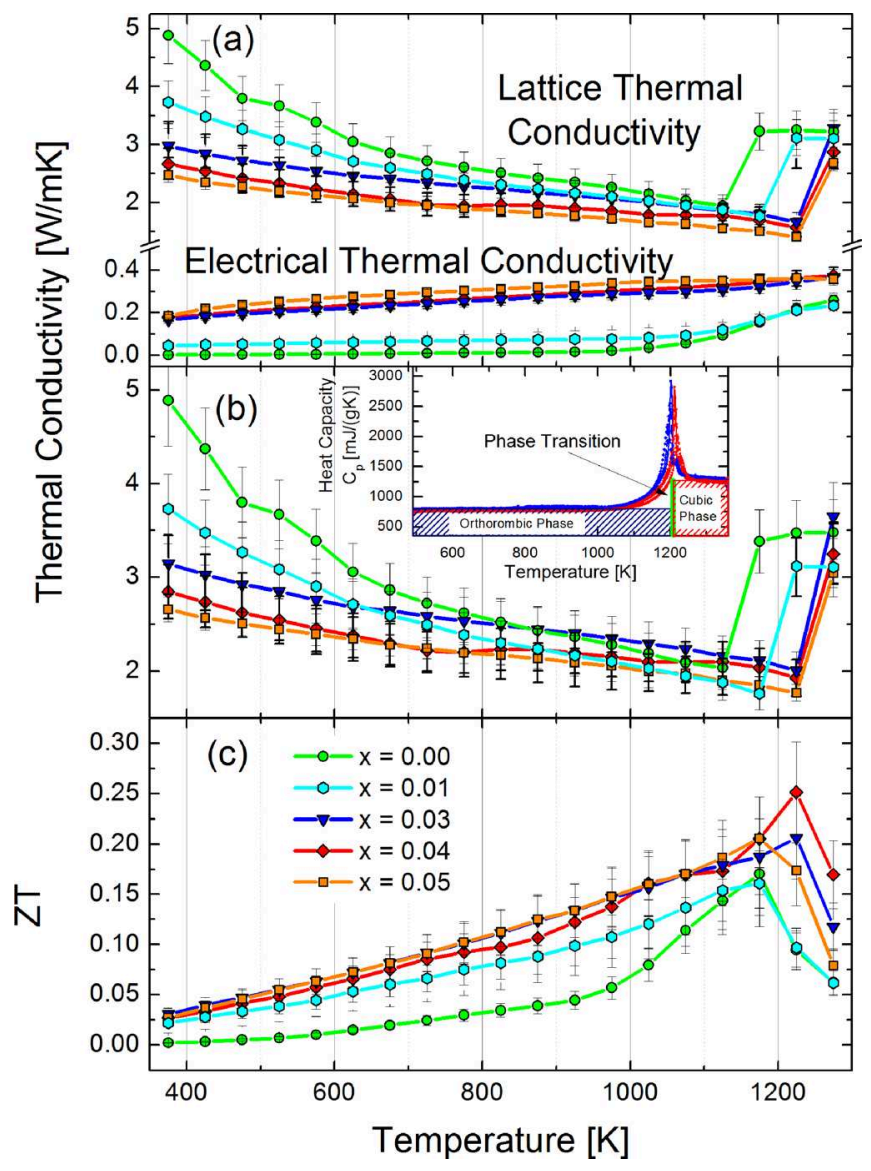

FIG. 9. Thermal conductivity and figure-of-merit $Z T$ of the series $\mathrm{CaMn}_{1-x} \mathrm{~W}_{x} \mathrm{O}_{3-\delta}(0.00 \leq x \leq 0.05)$ : (a) Lattice and electrical part of the thermal conductivity. (b) Total thermal conductivity. The inset shows a representative DSC measurement at different ramping rates $(5-20 \mathrm{~K} / \mathrm{min})$. Heating is red, cooling is blue. (c) Figure-of-merit $Z T$.
From $375 \mathrm{~K}$ to $900 \mathrm{~K}$ the ZT increases. The substituted samples exhibit a significantly better performance than the pristine $\mathrm{CaMnO}_{3-\delta}$. As discussed above, oxygen deficiency dominates the power factor in the high-temperature region and the impact of substitution is diminished. At $T=1175 \mathrm{~K}$, the $Z T$ of pristine $\mathrm{CaMnO}_{3-\delta}$ is higher $(Z T=0.17)$ than the $x=0.01$ sample $(Z T=0.16)$ due to additional charge carriers from oxygen loss. A maximum $Z T$ of 0.25 is observed for $\mathrm{CaMn}_{1-x} \mathrm{~W}_{x} \mathrm{O}_{3-\delta}$ with $x=0.04$ at $1225 \mathrm{~K}$. The broader high-ZT region of the tungsten-substituted samples is an important improvement over the pristine sample considering the material is to be subjected to large thermal gradients. The $Z T$ drops immediately following the orthorhombic to cubic phase transition.

\section{CONCLUSIONS}

The thermoelectric properties of the tungsten-substituted $\mathrm{CaMn}_{1-x} \mathrm{~W}_{x} \mathrm{O}_{3-\delta}(0.00 \leq x \leq 0.05)$ series are influenced by a combination of tungsten substitution and oxygen deficiencies incurred at high temperatures. The onset of oxygen loss occurs at higher temperatures with increasing tungsten content, and the loss is entirely reversible upon cooling. At temperatures around $1200 \mathrm{~K}$, an orthorhombic to cubic phase-transition is observed which is also delayed to higher temperatures with increasing substitution level.

The transport properties cannot be successfully described by Mott's adiabatic small-polaron conduction model. B-site substitutions are rather leading to the formation of impurity bands and a description with the CutlerMott model is more feasible. In the investigated temperature range, the band filling for all substitutions is sufficiently high to results in zero polaron-transport activation energy.

Variations in the Seebeck coefficient $S(T)$ in $\mathrm{CaMn}_{1-x} \mathrm{~W}_{x} \mathrm{O}_{3-\delta}$ are primarily due to the concentration of negative charge carriers. Tungsten $(d 6)$ provides additional negative charge carriers until the initiation of the reduction ( $360 \mathrm{~K} \leq T \leq T_{\text {red }}$ ). At $T \geq T_{\text {red }}$ additional electrons are gained by the loss of oxygen. Therefore in this temperature region, both the absolute Seebeck coefficient and electrical resistivity decrease systematically with increasing manganese(III) content. For pristine $\mathrm{CaMnO}_{3-\delta}$, the impact of oxygen deficiency is so dramatic that its high-temperature properties are similar to those of the substituted samples. Consequently, only if large temperature gradients are applied to the thermoelectric material, the medium-temperature properties, and therefore substitution, become crucial for enhancing the overall performance. The reduction in lattice thermal conductivity, in tungsten-substituted samples, is greatest at room temperature due to the predominance of mass-difference impurity scattering. A maximum $Z T$ of 0.25 is attained for $\mathrm{CaMn}_{1-x} \mathrm{~W}_{x} \mathrm{O}_{3-\delta}$ with $x=0.04$ at $1225 \mathrm{~K}$.

\section{ACKNOWLEDGMENTS}

The present work was financially supported by Competence Centre Energy and Mobility (HITTEC Project), the Swiss Federal Office of Energy (BfE), and Empa. Furthermore, the authors thank Ruben Rigort for his diligent help. 
${ }^{1}$ D. M. Rowe, Thermoelectrics Handbook: Macro to Nano (Taylor \& Francis, 2010).

${ }^{2}$ G. Snyder and E. Toberer, Nature Mater. 7, 105 (2008).

${ }^{3}$ P. Tomeš, M. Trottmann, C. Suter, M. H. Aguirre, A. Steinfeld, P. Haueter, and A. Weidenkaff, Materials 3, 2801 (2010).

${ }^{4}$ P. Tomeš, C. Suter, M. Trottmann, A. Steinfeld, and A. Weidenkaff, J. Mater. Res. 26, 1975 (2011).

${ }^{5}$ W. Brostow, T. Datashvili, H. E. H. Lobland, T. Hilbig, L. Su, C. Vinado, and J. White, J. Mater. Res. 27, 2930 (2012).

${ }^{6}$ S. Populoh, O. C. Brunko, K. Gałązka, W. Xie, and A. Weidenkaff, Materials 6, 1326 (2013).

${ }^{7}$ K. Gałązka, S. Populoh, L. Sagarna, L. Karvonen, W. Xie, A. Beni, P. Schmutz, J. Hulliger, and A. Weidenkaff, "Phase formation, stability and oxidation in (Ti,Zr,Hf)NiSn half-Heusler compounds," Phys. Status Solidi A (to be published).

${ }^{8}$ J. Leszczynski, K. T. Wojciechowski, and A. L. Malecki, J. Therm. Anal. Calorim. 105, 211 (2011).

${ }^{9}$ Z. Degang, T. Changwen, T. Shouqiu, L. Yunteng, and C. Lidong, J. Alloys Compd. 504, 552 (2010).

${ }^{10}$ J.-I. Tani, M. Takahashi, and H. Kido, IOP Conference Series: Materials Science and Engineering (IOP Publishing, 2011), Vol. 18, p. 142013.

${ }^{11}$ A. Maignan, S. Hebert, L. Pi, D. Pelloquin, C. Martin, C. Michel, M. Hervieu, and B. Raveau, Cryst. Eng. 5, 365 (2002).

${ }^{12}$ K. Koumoto, R. Funahashi, E. Guilmeau, Y. Miyazaki, A. Weidenkaff, Y. Wang, C. Wan, and X. D. Zhou, J. Am. Ceram. Soc. 96, 1 (2013).

${ }^{13}$ L. Bocher, M. H. Aguirre, D. Logvinovich, A. Shkabko, R. Robert, M. Trottmann, and A. Weidenkaff, Inorg. Chem. 47, 8077 (2008).

${ }^{14}$ S. Populoh, M. Trottmann, O. C. Brunko, P. Thiel, and A. Weidenkaff, Funct. Mater. Lett. 06, 1340012 (2013).

${ }^{15}$ M. Ohtaki, H. Koga, T. Tokunaga, K. Eguchi, and H. Arai, J. Solid State Chem. 120, 105 (1995).

${ }^{16}$ D. Flahaut, T. Mihara, R. Funahashi, N. Nabeshima, K. Lee, H. Ohta, and K. Koumoto, J. Appl. Phys. 100, 084911 (2006).

${ }^{17}$ P. X. Thao, T. Tsuji, M. Hashida, and Y. Yamamura, J. Ceram. Soc. Jpn. 111, 544 (2003).

${ }^{18}$ A. Urushibara, Y. Moritomo, T. Arima, A. Asamitsu, G. Kido, and Y. Tokura, Phys. Rev. B 51, 14103 (1995).

${ }^{19}$ A. Weidenkaff, R. Robert, M. Aguirre, L. Bocher, T. Lippert, and S. Canulescu, Renewable Energy 33, 342 (2008).

${ }^{20}$ B. Raveau, Y. M. Zhao, C. Martin, M. Hervieu, and A. Maignan, J. Solid State Chem. 149, 203 (2000)

${ }^{21}$ L. Pi, S. Hébert, C. Martin, A. Maignan, and B. Raveau, Phys. Rev. B 67, 024430 (2003).

${ }^{22}$ G. Xua, R. Funahashic, Q. Pu, B. Liu, R. Tao, G. Wang, and Z. Ding, Solid State Ionics 171, 147 (2004).

${ }^{23}$ B. Raveau, Y. M. Zhao, C. Martin, M. Hervieu, and A. Maignan, J. Solid State Chem. 149, 203 (2000).

${ }^{24}$ E. I. Leonidova, I. A. Leonidov, M. V. Patrakeev, and V. L. Kozhevnikov, J. Solid State Electrochem. 15, 1071 (2011).

${ }^{25}$ E. I. Goldyreva, I. A. Leonidov, M. V. Patrakeev, and V. L. Kozhevnikov, J. Solid State Electrochem. 16, 1187 (2013).

${ }^{26}$ D. Moser, L. Karvonen, S. Populoh, M. Trottmann, and A. Weidenkaff, Solid State Sci. 13, 2160-2164 (2011).

${ }^{27}$ S. V. Trukhanov, N. V. Kasper, I. O. Troyanchuk, M. Tovar, H. Szymczak, and K. Bärner, J. Solid State Chem. 169, 85 (2002).

${ }^{28}$ L. Bocher, M. H. Aguirre, R. Robert, D. Logvinovich, S. Bakardjieva, J. Hejtmanek, and A. Weidenkaff, Acta Mater. 57, 5667 (2009).

${ }^{29}$ E. I. Goldyreva, I. A. Leonidov, M. V. Patrakeev, and V. L. Kozhevnikov, J. Solid State Electrochem. 17, 1449 (2013).

${ }^{30}$ K. R. Poeppelmeier, M. E. Leonowicz, J. C. Scanlon, J. M. Longo, and W. B. Yelon, J. Solid State Chem. 45, 71 (1982).

${ }^{31}$ C. C. K. Chiang and K. R. Poeppelmeier, Mater. Lett. 12, 102 (1991).

${ }^{32}$ L. Pi, S. Zhang, W. Tong, S. Tan, and Y. Zhang, Solid State Commun. 139, 460 (2006).
${ }^{33}$ M. Miclau, J. Hejtmanek, R. Retoux, K. Knizek, Z. Jirak, R. Frésard, A. Maignan, S. Hébert, M. Hervieu, and C. Martin, Chem. Mater. 19, 4243 (2007).

${ }^{34}$ D. S. Alfaruq, J. Eilertsen, P. Thiel, M. H. Aguirre, E. Otal, S. Populoh, S. Yoon, and A. Weidenkaff, MRS Proc. 1490, 3-8 (2013).

${ }^{35}$ M. G. Holland, Phys. Rev. 132, 2461 (1963).

${ }^{36}$ E. Krupicka, A. Reller, and A. Weidenkaff, Cryst. Eng. 5, 195 (2002).

${ }^{37}$ A. Weidenkaff, Adv. Eng. Mater. 6, 709 (2004).

${ }^{38}$ P. C. Mürau, Anal. Chem. 33, 1125 (1961).

${ }^{39}$ A. L. Bail, H. Duroy, and J. L. Fourquet, Mater. Res. Bull. 23, 447 (1988).

${ }^{40}$ J. Rodríguez-Carvajal, Phys. B: Condens. Matter 192, 55 (1993).

${ }^{41}$ L. Sagarna, K. Z. Rushchanskii, A. Maegli, S. Yoon, S. Populoh, A. Shkabko, S. Pokrant, M. Ležaić, R. Waser, and A. Weidenkaff, J. Appl. Phys. 114, 033701 (2013).

${ }^{42}$ W. K. Chu, J. W. Mayer, and M. A. Nicolet, Backscattering Spectrometry (Academic Press, 1978).

${ }^{43}$ L. R. Doolittle, Nucl. Instrum. Methods Phys. Res. B 15, 227 (1986).

${ }^{44}$ S. Populoh, M. H. Aguirre, O. C. Brunko, K. Galazka, Y. Lu, and A. Weidenkaff, Scr. Mater. 66, 1073 (2012).

${ }^{45}$ L. Bocher, M. Aguirre, R. Robert, D. Logvinovich, S. Bakardjieva, J. Hejtmanek, and A. Weidenkaff, Acta Mater. 57, 5667-5680 (2009).

${ }^{46}$ A. R. Denton and N. W. Ashcroft, Phys. Rev. A 43, 3161 (1991).

${ }^{47}$ S. Block and C. R. Hubbard, in Proceedings of a Symposium on Accuracy in Powder Diffraction held at the National Bureau of Standards, Gaithersburg, MD, 11-15 June 1979 (Department of Commerce, National Bureau of Standards, Washington, 1979).

${ }^{48}$ A. Leineweber and E. J. Mittemeijer, Adv. X-Ray Anal. 46, 43 (2003).

${ }^{49}$ J. Eilertsen, R. Berthelot, A. W. Sleight, and M. A. Subramanian, J. Solid State Chem. 190, 238 (2012).

${ }^{50}$ R. J. Colton, A. M. Guzman, and J. W. Rabalais, J. Appl. Phys. 49, 409 (1978).

${ }^{51}$ R. D. Shannon, Acta Crystallogr., Sect. A: Cryst. Phys., Diffr., Theor. Gen. Crystallogr. 32, 751 (1976).

${ }^{52}$ Y. Wang, Y. Sui, X. Wang, and W. Su, J. Phys. D: Appl. Phys. 42, 055010 (2009).

${ }^{53}$ M. Coey, Nature 430, 155 (2004).

${ }^{54}$ J. Herrero-Martín, J. García, G. Subías, J. Blasco, and M. C. Sánchez, Phys. Rev. B 70, 24408 (2004).

${ }^{55}$ W. Luo, A. Franceschetti, M. Varela, J. Tao, S. Pennycook, and S. Pantelides, Phys. Rev. Lett. 99, 36402 (2007).

${ }^{56}$ J. Goodenough, Annu. Rev. Mater. Sci. 28, 1 (1998).

${ }^{57}$ L. Bocher, R. Robert, M. H. Aguirre, S. Malo, S. Hébert, A. Maignan, and A. Weidenkaff, Solid State Sci. 10, 496 (2008).

${ }^{58}$ C. S. Sanmathi, Y. Takahashi, D. Sawaki, Y. Klein, R. Retoux, I. Terasaki, and J. G. Noudem, Mater. Res. Bull. 45, 558 (2010).

${ }^{59}$ G. Zhao, V. Smolyaninova, W. Prellier, and H. Keller, Phys. Rev. Lett. 84, 6086 (2000).

${ }^{60}$ G.-M. Zhao, K. Conder, H. Keller, and K. A. Muller, Nature 381, 676 (1996).

${ }^{61}$ C. H. Booth, F. Bridges, G. H. Kwei, J. M. Lawrence, A. L. Cornelius, and J. J. Neumeier, Phys. Rev. Lett. 80, 853 (1998).

${ }^{62}$ A. Bosman and C. Crevecoeur, Phys. Rev. 144, 763 (1966).

${ }^{63}$ N. F. S. Mott, in Electronic Processes in Non-Crystalline Materials, edited by N. F. Mott and E. A. Davis (Clarendon Press, Oxford, 1971).

${ }^{64}$ Y. Wang, Y. Sui, J. Cheng, X. Wang, Z. Lu, and W. Su, J. Phys. Chem. C 113, 12509 (2009).

${ }^{65}$ C.-J. Liu, A. Bhaskar, and J. J. Yuan, Appl. Phys. Lett. 98, 214101 (2011).

${ }^{66}$ M. Cutler and N. F. Mott, Phys. Rev. 181, 1336 (1969).

${ }^{67}$ Y. Murano, M. Matsukawa, S. Ohuchi, S. Kobayashi, S. Nimori, R. Suryanarayanan, K. Koyama, and N. Kobayashi, Phys. Rev. B 83, 054437 (2011).

${ }^{68}$ B. Fisher, L. Patlagan, G. M. Reisner, and A. Knizhnik, Phys. Rev. B 61, 470 (2000).

${ }^{69}$ G. Chester and A. Thellung, Proc. Phys. Soc. 77, 1005 (1961).

${ }^{70}$ T. M. Tritt, Thermal Conductivity: Theory, Properties, and Applications (Springer, 2004). 